\title{
The Experimental TASK-1 Potassium Channel Inhibitor A293 Can Be Employed for Rhythm Control of Persistent Atrial Fibrillation in a Translational Large Animal Model
}

\author{
Hélène Le Ribeuz ${ }^{1,2,3}$, David Montani ${ }^{1,2,3}$ and Fabrice Antigny ${ }^{1,2,3 *}$ \\ ${ }^{1}$ Université Paris-Saclay, Faculté de Médecine, Le Kremlin-Bicêtre, France, ${ }^{2}$ INSERM UMR_S 999 《Hypertension \\ Pulmonaire: Physiopathologie et Innovation Thérapeutique 》, Hôpital Marie Lannelongue, Le Plessis-Robinson, France, \\ ${ }^{3}$ Assistance Publique - Hôpitaux de Paris (AP-HP), Service de Pneumologie et Soins Intensifs Respiratoires, Centre de \\ Référence de l'Hypertension Pulmonaire, Hôpital Bicêtre, Le Kremlin-Bicêtre, France
}

Keywords: TASK-1, KCNK3, pulmonary hypertension, atrial fibrillation, A293

\section{INTRODUCTION}

The authors report in a porcine model of persistent atrial fibrillation (AF) that long term in vivo pharmacological inhibition of TASK-1 potassium channels with A293 compound (1 mg/kg/day) has antiarrhythmic effects, suggesting that TASK-1 inhibition can be used to counteract rhythm abnormalities in AF patients (Wiedmann et al., 2020b). Previously, the same group, using in

Edited by:

T. Alexander Quinn

Dalhousie University, Canada

Reviewed by:

Steven Feinmark,

Columbia University, United States

*Correspondence:

Fabrice Antigny

fabrice.antigny@universite-paris-saclay.fr

Specialty section:

This article was submitted to Cardiac Electrophysiology,

a section of the journal

Frontiers in Physiology

Received: 15 February 2021 Accepted: 15 March 2021 Published: 12 April 2021

Citation:

Le Ribeuz H, Montani D and Antigny F (2021) The Experimental TASK-1 Potassium Channel Inhibitor A293

Can Be Employed for Rhythm Control of Persistent Atrial Fibrillation in a Translational Large Animal Model.

Front. Physiol. 12:668267. doi: 10.3389/fphys.2021.668267 vitro experiments described an upregulation of TASK-1 in patients with AF, which was associated with a shortening of the human atrial action potential (Schmidt et al., 2015). Moreover, using isolated human and porcine atrial cardiomyocytes, they also demonstrated that pharmacological inhibition of atrial TASK-1 induces antiarrhythmic effects in vitro as well as in silico. They found that short-term in vivo pharmacological inhibition of TASK-1 by A293 ( $1 \mathrm{mg} / \mathrm{Kg} /$ day) does not alter the surface ECG parameters of healthy control pigs (Wiedmann et al., 2020a). Using A293, they also showed that pharmacological inhibition of TASK-1 prolongs action potential duration in atrial myocytes obtained from patients with chronic atrial fibrillation in vitro (Schmidt et al., 2015). Undoubtedly, all these results and the fact that mutations were found in the KCNK3 gene (coding TASK-1 channel) from some patients with AF (Liang et al., 2014) clearly demonstrated that TASK-1 is crucially involved in AF, and clearly indicate that this potassium channel should be an interesting therapeutic target in AF.

\section{SUBSECTIONS RELEVANT FOR THE SUBJECT}

However, TASK-1 is expressed in several cell types, including pulmonary arterial smooth muscle cells (PASMCs) and pulmonary arterial endothelial cells (PAECs), in human, pigs and rats. Moreover, since 2013, 12 different KCNK3 mutations have been identified in at least 19 patients from different cohorts of patients with pulmonary arterial hypertension (PAH) (Le Ribeuz et al., 2020a). Heritable PAH due to KCNK3 mutations is characterized by autosomal dominant inheritance with incomplete penetrance (Morrell et al., 2019). To date, all KCNK3 mutations analyzed by whole-cell patch-clamp analysis have led to loss-of-function (LOF) of the TASK1 channel (Le Ribeuz et al., 2020a), indicating that TASK-1 LOF at least predisposes to the development of PAH. Indeed, previous studies showed that TASK-1 inactivation by siRNA or pharmacological inhibition (A293 compound) in human PASMCs (hPASMCs) and rat PASMCs 
leads to the depolarization of resting membrane potential (Olschewski et al., 2006; Antigny et al., 2016). We also found in vitro in hPASMCs that TASK-1 LOF (siRNA or inhibition with A293) enhances the proliferation of hPASMCs (Lambert et al., 2019). In control hPAECs and hPASMCs we recently found that the loss of TASK-1 expression by a specific siRNA induces deregulation of several signaling pathways involved in the control of cell proliferation, cell migration, cell apoptosis, and cell metabolism (Le Ribeuz et al., 2020b). In association with PASMC depolarization, we found that TASK-1 inhibition with A293 or Task-1-LOF-mutation causes pulmonary artery vasoconstriction in rats (Antigny et al., 2016; Lambert et al., 2019).

Additionally, we found that in vivo inhibition of TASK-1 in rats with A293 at $10 \mathrm{mg} / \mathrm{kg} /$ day induced the development of significant early signs of $\mathrm{PAH}$, with abnormal elevation of right ventricular systolic pressure (RVSP), abnormal pulmonary vascular cell proliferation, pulmonary vessel remodeling, and lung inflammation (Antigny et al., 2016) as well as RV hypertrophy, RV fibrosis, RV inflammation, and a subsequent decrease in RV performance (Lambert et al., 2018). Using Kcnk3-LOF mutated rats, we recently confirmed that TASK-1 LOF is a key event in PAH pathogenesis, promoting the elevation of RVSP, distal lung neomuscularization, perivascular extracellular matrix activation, overactivation of proliferative and survival signaling pathways and alteration of RV cardiomyocyte excitability (Lambert et al., 2019). Importantly, in contrast to other cell types, TASK-1 was the unique TASK channel expressed in the pulmonary vasculature (Olschewski et al., 2017) making pulmonary vascular cells more susceptible to TASK-1 channel inhibition than other tissues.

\section{DISCUSSION}

In line with these results, Wiedmann et al., found that chronic in vivo inhibition of TASK-1 (for 14 days) in a porcine model of persistent AF was associated with an increase in pulmonary arterial pressure (Wiedmann et al., 2020b), confirming that TASK-1 is a crucial channel for the maintenance of pulmonary vasculature homeostasis. Indeed, the TASK1 channel contributes to the resting membrane potential of several additional cells, including neurons, carotid bodies, and in adrenal glands. Regarding the role of TASK-1 in aldosterone

\section{REFERENCES}

Antigny, F., Hautefort, A., Meloche, J., Belacel-Ouari, M., Manoury, B., RuckerMartin, C., et al. (2016). Potassium channel subfamily K member 3 (KCNK3) contributes to the development of pulmonary arterial hypertension. Circulation 133, 1371-1385. doi: 10.1161/CIRCULATIONAHA.115.020951

Bayliss, D. A., Barhanin, J., Gestreau, C., and Guyenet, P. G. (2015). The role of pHsensitive TASK channels in central respiratory chemoreception. Pflugers Arch. 467, 917-929. doi: 10.1007/s00424-014-1633-9

Bittner, S., Bauer, M. A., Ehling, P., Bobak, N., Breuer, J., Herrmann, A. M., et al. (2012). The TASK1 channel inhibitor A293 shows efficacy production in mice (Heitzmann et al., 2008; Chen et al., 2015), the measurement of aldosterone level in "AF-like pigs" treated with A293 may be informative. In pancreatic $\alpha$-cell, TASK-1 inhibition modulates glucose-dependent inhibition of glucagon secretion by regulating the $\alpha$-cell excitability (Dadi et al., 2015), in patients potentially treated with TASK-1 inhibitors glycaemia should be regularly assessed. Indeed, as TASK-1 channel plays a role in the chemosensory control of breathing in mice (Bayliss et al., 2015; Buehler et al., 2017), it would be of interest to report if the authors have noticed any effects on animal respiration or gas exchanges. Additionally, TASK-1 is functionally expressed in $\mathrm{T}$ lymphocytes, contributing to outward- $\mathrm{K}^{+}$currents, and the in vitro and in vivo selective TASK1 inhibition reduces the $\mathrm{T}$ cell proliferation and cytokine production (Meuth et al., 2008; Bittner et al., 2012; Bittner and Meuth, 2013), which could have profound consequence for autoimmune response in patients treated with TASK-1 channels blockers. Finally, in mice the knockdown of TASK-1 significantly decreased the formation of blastocyst by $38 \%$ suggesting that TASK-1 is required for mouse embryonic development (Hur et al., 2012). To avoid any risk during embryonic development, TASK-1 blockers administration should not be administrated to women who are or wish to be pregnant.

For all these physiological role played by TASK-1 in several tissues, the in vivo pharmacological inhibition of TASK-1 should be extremely managed in treated-patients with AF.

Based on these results, one can hypothesize that A293 may induce $\mathrm{PAH}$ and right ventricular dysfunction in humans. Given the long history of drug-induced PAH [anorexigens (Montani et al., 2013), tyrosine kinase inhibitors (Weatherald et al., 2017), and chemotherapy (Certain et al., 2020)], we wish to convey the need for the close monitoring and screening echocardiography for PAH in patients chronically treated with TASK-1 inhibitors.

\section{AUTHOR CONTRIBUTIONS}

HL, DM, and FA drafted the manuscript. All authors reviewed and revised the final version and approved manuscript submission.

\section{FUNDING}

This work was supported by Agence Nationale de la Recherche (ANR-18-CE14-0023). in a mouse model of multiple sclerosis. Exp. Neurol. 238, 149-155. doi: 10.1016/j.expneurol.2012.08.021

Bittner, S., and Meuth, S. G. (2013). Targeting ion channels for the treatment of autoimmune neuroinflammation. Ther. Adv. Neurol. Disord. 6, 322-336. doi: $10.1177 / 1756285613487782$

Buehler, P. K., Bleiler, D., Tegtmeier, I., Heitzmann, D., Both, C., Georgieff, M., et al. (2017). Abnormal respiration under hyperoxia in TASK-1/3 potassium channel double knockout mice. Respir. Physiol. Neurobiol. 244, 17-25. doi: 10.1016/j.resp.2017.06.009

Certain, M.-C., Chaumais, M.-C., Jaïs, X., Savale, L., Seferian, A., Parent, F., et al. (2020). Characteristics and long-term outcomes of pulmonary 
venoocclusive disease induced by mitomycin C. Chest 159, 1197-1207. doi: $10.1016 /$ j.chest.2020.09.238

Chen, A. X., Nishimoto, K., Nanba, K., and Rainey, W. E. (2015). Potassium channels related to primary aldosteronism: expression similarities and differences between human and rat adrenals. Mol. Cell. Endocrinol. 417, 141-148. doi: 10.1016/j.mce.2015.09.011

Dadi, P. K., Luo, B., Vierra, N. C., and Jacobson, D. A. (2015). TASK-1 potassium channels limit pancreatic $\alpha$-cell calcium influx and glucagon secretion. Mol. Endocrinol. 29, 777-787. doi: 10.1210/me.2014-1321

Heitzmann, D., Derand, R., Jungbauer, S., Bandulik, S., Sterner, C., Schweda, F., et al. (2008). Invalidation of TASK1 potassium channels disrupts adrenal gland zonation and mineralocorticoid homeostasis. EMBO J. 27, 179-187. doi: 10.1038/sj.emboj.7601934

Hur, C.-G., Kim, E.-J., Cho, S.-K., Cho, Y.-W., Yoon, S.-Y., Tak, H.-M., et al. (2012). $\mathrm{K}(+)$ efflux through two-pore domain $\mathrm{K}(+)$ channels is required for mouse embryonic development. Reprod. Camb. Engl. 143, 625-636. doi: 10.1530/REP-11-0225

Lambert, M., Boet, A., Rucker-Martin, C., Mendes-Ferreira, P., Capuano, V., Hatem, S., et al. (2018). Loss of KCNK3 is a hallmark of RV hypertrophy/dysfunction associated with pulmonary hypertension. Cardiovasc. Res. 114, 880-893. doi: 10.1093/cvr/cvy016

Lambert, M., Capuano, V., Boet, A., Tesson, L., Bertero, T., Nakhleh, M. K., et al. (2019). Characterization of Kcnk3-mutated rat, a novel model of pulmonary hypertension. Circ. Res. 125, 678-695. doi: 10.1161/CIRCRESAHA.119.314793

Le Ribeuz, H., Capuano, V., Girerd, B., Humbert, M., Montani, D., and Antigny, F. (2020a). Implication of potassium channels in the pathophysiology of pulmonary arterial hypertension. Biomolecules 10:1261. doi: 10.3390/biom10091261

Le Ribeuz, H., Dumont, F., Ruellou, G., Lambert, M., Balliau, T., Quatredeniers, M., et al. (2020b). Proteomic analysis of KCNK3 loss of expression identified dysregulated pathways in pulmonary vascular cells. Int. J. Mol. Sci. 21:7400. doi: $10.3390 /$ ijms 21197400

Liang, B., Soka, M., Christensen, A. H., Olesen, M. S., Larsen, A. P., Knop, F. K., et al. (2014). Genetic variation in the two-pore domain potassium channel, TASK-1, may contribute to an atrial substrate for arrhythmogenesis. J. Mol. Cell. Cardiol. 67, 69-76. doi: 10.1016/j.yjmcc.2013.12.014

Meuth, S. G., Bittner, S., Meuth, P., Simon, O. J., Budde, T., and Wiendl, H. (2008). TWIK-related acid-sensitive $\mathrm{K}+$ channel 1 (TASK1) and TASK3 critically influence $\mathrm{T}$ lymphocyte effector functions. J. Biol. Chem. 283, 14559-14570. doi: 10.1074/jbc.M80063 7200
Montani, D., Seferian, A., Savale, L., Simonneau, G., and Humbert, M. (2013) Drug-induced pulmonary arterial hypertension: a recent outbreak. Eur. Respir. Rev. Off. J. Eur. Respir. Soc. 22, 244-250. doi: 10.1183/09059180.00003313

Morrell, N. W., Aldred, M. A., Chung, W. K., Elliott, C. G., Nichols, W. C., Soubrier, F., et al. (2019). Genetics and genomics of pulmonary arterial hypertension. Eur. Respir. J. 53:1801899. doi: 10.1183/13993003.01899-2018

Olschewski, A., Li, Y., Tang, B., Hanze, J., Eul, B., Bohle, R. M., et al. (2006). Impact of TASK-1 in human pulmonary artery smooth muscle cells. Circ. Res. 98, 1072-1080. doi: 10.1161/01.RES.0000219677.12988.e9

Olschewski, A., Veale, E. L., Nagy, B. M., Nagaraj, C., Kwapiszewska, G., Antigny, F., et al. (2017). TASK-1 (KCNK3) channels in the lung: from cell biology to clinical implications. Eur. Respir. J. 50:1700754. doi: 10.1183/13993003.00754-2017

Schmidt, C., Wiedmann, F., Voigt, N., Zhou, X.-B., Heijman, J., Lang, S., et al. (2015). Upregulation of $\mathrm{K}(2 \mathrm{P}) 3.1 \mathrm{~K}+$ current causes action potential shortening in patients with chronic atrial fibrillation. Circulation 132, 82-92. doi: 10.1161/CIRCULATIONAHA.114.012657

Weatherald, J., Chaumais, M.-C., and Montani, D. (2017). Pulmonary arterial hypertension induced by tyrosine kinase inhibitors. Curr. Opin. Pulm. Med. 23, 392-397. doi: 10.1097/MCP.0000000000000412

Wiedmann, F., Beyersdorf, C., Zhou, X., Büscher, A., Kraft, M., Nietfeld, J., et al. (2020a). Pharmacologic TWIK-related acid-sensitive K+ channel (TASK-1) potassium channel inhibitor A293 facilitates acute cardioversion of paroxysmal atrial fibrillation in a porcine large animal model. J. Am. Heart Assoc. 9:e015751. doi: 10.1161/JAHA.119.015751

Wiedmann, F., Beyersdorf, C., Zhou, X.-B., Kraft, M., Foerster, K. I., El-Battrawy, I., et al. (2020b). The experimental TASK-1 potassium channel inhibitor A293 can be employed for rhythm control of persistent atrial fibrillation in a translational large animal model. Front. Physiol. 11:629421. doi: 10.3389/fphys.2020.629421

Conflict of Interest: The authors declare that the research was conducted in the absence of any commercial or financial relationships that could be construed as a potential conflict of interest.

Copyright (c) 2021 Le Ribeuz, Montani and Antigny. This is an open-access article distributed under the terms of the Creative Commons Attribution License (CC BY). The use, distribution or reproduction in other forums is permitted, provided the original author(s) and the copyright owner(s) are credited and that the original publication in this journal is cited, in accordance with accepted academic practice. No use, distribution or reproduction is permitted which does not comply with these terms. 